\title{
STRATEGIC GREEN MANAGEMENT AND COMPETITIVE ADVANTAGE
}

Soon Tay, California State University, Fullerton, California, USA

Peng Chan, California State University, Fullerton, California, USA

Lam Nguyen, Bloomsburg University of Pennsylvania, Pennsylvania, USA

dx.doi.org/10.18374/RBR-13-4.12

\begin{abstract}
The intention of this paper is to explore the concept of green management practice in firms where sustainable green strategy is identified and utilized to achieve competitive advantage. The value proposition of green strategy is analyzed with the effect of ISO 14001 accreditation to benefit the firm's performance is sustainable in the long term. Through recognizing the importance of green strategy, the analysis further expands the firm perception in green management impact to firm's bottom line. Hence, the model of strategic green management broadened the concept of green strategy adaptation in firm operation to improve its brand image and bottom line. Whereas, the paper recognized the competitive advantage a firm could achieve with green management utilization in the firm's operation to reach the objective of benefiting the environment and the community.
\end{abstract}

Keywords: Green Strategies; Competitive Advantage 